\title{
Binocular Vision and Ipsilateral Retinal Projections in Relation to Eye and Forelimb Coordination
}

\author{
Matz Larsson ${ }^{\mathrm{a}, \mathrm{b}}$ \\ ${ }^{a}$ The Cardiology Clinic, Örebro University Hospital, Örebro, and ${ }^{\mathrm{b}}$ The Institute of Environmental Medicine, \\ Karolinska Institute, Stockholm, Sweden
}

\section{Key Words}

Optic chiasm • Evolution - Dexterity · Ipsilateral retinal projection $\cdot$ Nonmammalian vertebrate $\cdot$ Binocular vision Primate

\begin{abstract}
It is commonly proposed that the number of fibers that do not cross in the optic chiasm (OC) is proportional to the size of the binocular visual field, and that the major advantage of binocular vision is acute depth perception. I present an alternative, an 'eye-forelimb' (EF) hypothesis, suggesting that alterations in the $O C$ influence the length of neural pathways that transmit visual information to motor nuclei and somatosensory areas involved in forelimb coordination. Evolutionary processes resulting in increased ipsilateral retinal projections (IRP) are of adaptive value in animals that regularly use the forelimbs in a frontal position, while evolutionary change towards reduced IRP is of value for animals that mainly use the forelimbs in lateral positions. Primates and cats, to a large extent, use visually guided forelimb maneuvers, and both groups have high proportions of IRP. The fact that vertebrates' IRP arise exclusively from the temporal retina supports the hypothesis, since IRP from the nasal retina would increase the length of neural pathways involved in forelimb coordination. The EF hypothesis offers new perspectives on why a high proportion of IRP among early limbless verte-
\end{abstract}

brates became reduced during the evolution of laterally situated limbs, and why reptiles that lost their limbs (snakes) evolved more IRP. Anatomical, neurophysiological, phylogenetic, ontogenetic and ecological data suggest that mutations changing the proportions of ipsilateral visual connections in the $\mathrm{OC}$ may have selective value for EF coordination.

Copyright $\odot 2011$ S. Karger AG, Basel

\section{Introduction}

Harris [1904] wrote: 'Binocular vision is clearly of great assistance in the accurate use of the hand for fine movements ..., and several authors after that have proposed a significant association between binocular vision and eye-hand control, e.g. Elliot Smith [1928], Le Gros Clarke [1934] and Hughes [1977]. However, the architecture of neural pathways between the eye and the brain in relation to forelimb control, which is the focus of this review, has been little discussed. The structure of the ventral diencephalon midline, where retinal ganglion cell (RGC) axons partially decussate, or cross, is called the optic chiasm (OC). In primates, approximately $45 \%$ of RGCs project to targets on the same side [Fukuda et al., 1989]. Many predatory mammals, such as the Felidae, have frontally positioned eyes and a significant degree of ipsilateral retinal projection (IRP) [Jeffery and Erskine,

\section{KARGER \\ Fax +4161306 1234 \\ E-Mail karger@karger.ch}

www.karger.com
(C) 2011 S. Karger AG, Basel

0006-8977/11/0774-0219\$38.00/0

Accessible online at:

www.karger.com/bbe
Matz Larsson, $\mathrm{MD}, \mathrm{PhD}$

The Cardiology Clinic

Örebro University Hospital

SE-701 85 Örebro (Sweden)

Tel. +46 19602 5596, E-Mail matz.larsson@orebroll.se 
2005]. Domestic cats display 30\% IRP [Herrera and Mason, 2007], while the ferret possesses approximately $8 \%$ IRP [Henderson, 1985; Morgan et al., 1987]. Mammals with laterally positioned eyes have a low degree of IRP [Herrera and Mason, 2007]. In rodents, the uncrossed component is about $2-3 \%$ [Petros et al., 2008]. Newton argued that binocular vision requires that fibers from each retina allocate to both sides of the brain [Soury, 1899; Newton, 1931; Polyak, 1957]. Johannes Müller proposed that this could be achieved either by splitting each retinal fiber or by partial decussation of the optic nerve in the OC [Polyak, 1957]. Bernhard von Gudden showed that the OC contains both crossed and uncrossed retinal fibers, and Ramon y Cajal [1972] observed that the degree of hemidecussation varies among species [Polyak, 1957; Ramon y Cajal, 1972]. Walls [1942] formalized the law of Newton-Müller-Gudden (NGM), which proposes that the number of fibers that do not cross the midline is proportional to the size of the binocular visual field. That is, the degree of optic fiber decussation in the chiasm is inversely related to frontal orientation of the optical axes of the eyes. A controversial aspect of the NGM law is the considerable interspecific variation in ipsilateral visual projections in nonmammalian species [Ward et al., 1995]. This variation has not been shown to be related to an overlap of visual fields, mode of life, or taxonomic position. I present an eye-forelimb (EF) hypothesis, based on the idea that alterations in the OC will influence the length of neural pathways that transmit visual information to motor nuclei and somatosensory areas involved in forelimb coordination. Mutations resulting in increased IRP should be of adaptive value in animals that regularly use their forelimbs frontally, while mutations towards reduced IRP will be of adaptive value for animals that mainly use the forelimbs laterally. The aim of this review is to evaluate the EF hypothesis in vertebrates in relation to OC formation, hemidecussation, binocular vision, and motor behavior.

\section{The EF Hypothesis}

\section{Manual Performance in the Right and Left Visual Hemispheres}

Berlucchi et al. [1971] suggested that the reactions of the hand to stimuli presented in the ipsilateral visual hemifield are integrated in the contralateral hemisphere. This means that when the right hand performs a task in the right visual field (RVF), the visual information of the right hand's location in space is processed in the left hemisphere, which also processes motor reactions of the right hand. On the contrary, right hand maneuvers and visual stimuli in the left visual field require coordination of the visual cortex in the right hemisphere and the motor cortex in the left hemisphere; hence such crossed reactions should contain at least one more synaptic link. Thus the right hand should react faster to stimuli presented in the RVF and vice versa for the left hand. Fisk and Goodale [1985] verified that the laterality of the target was the single most important determinant of the manner in which a reaching movement is executed. Their research also demonstrated a remarkably close timing of eye and hand during a reaching movement. Aziz-Zadeh et al. [2006] showed that both brain hemispheres displayed more rapid motor responses to contralateral visual stimuli as compared to ipsilateral stimuli.

Evolutionary Change in the OC and Effects on Neural Pathways among Cooperating Brain Areas

In vertebrates, motor nuclei and somatosensory areas of the limbs are situated in the contralateral cerebral hemisphere. Figure 1 shows visual pathways to the superior colliculus in three types of animals, a vertebrate without limbs, a vertebrate with laterally situated limbs, and a primate. The superior colliculus is a component of the tectum, which integrates visual, somatosensory and auditory information. In addition, two other major targets of visual information from the retina, the suprachiasmatic nucleus of the hypothalamus and the pretectum, are involved in circadian rhythm and pupillary light responses. The proportion of IRP in these non-image forming visual pathways is not related to the degree of binocular vision [Magnin et al., 1989].

If the eyes are laterally positioned and if only crossed axons exist in the OC, visual information from the RVF will be processed in the left brain hemisphere (fig. 1b). Fish, birds, and reptiles, for anatomical or functional reasons, rarely use their forelimbs frontally. Thus, evolutionary changes towards ipsilaterality would have no selective value with respect to EF coordination in these animals. A consequence, for example in crocodilians, would be that an increased fraction of visual information about the right forelimb position is directed to the right cerebral hemisphere, where it is not likely to be especially useful in eye-directed forelimb coordination. However, a change in the opposite direction (i.e. less IRP and more crossed retinal projections) would increase transmission of visual information about the right forelimb to the left hemisphere, which theoretically could lead to improved EF coordination (fig. 1b). That may also be relevant for dol- 


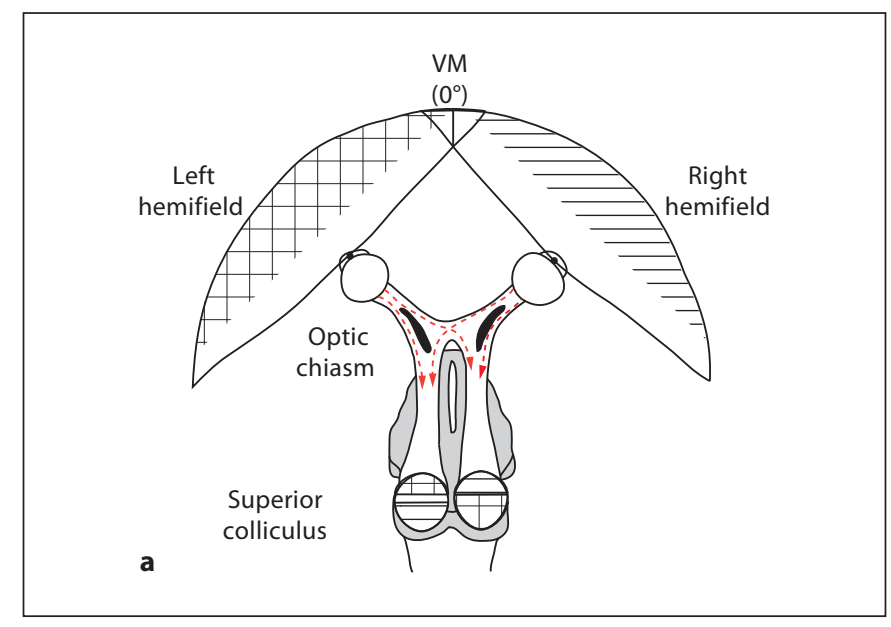

Fig. 1. Visual pathways in three principal types of vertebrates. The figures only show retinal pathways to the superior colliculus, but principles for neural pathway length to the primary visual cortex will be analogous. (Visual pathways to the suprachiasmatic nucleus of the hypothalamus and the pretectum are not presented.) a Schematic of optic pathways in limbless vertebrates, e.g. cyclostomes, snakes and cecilians. Limbless animals in general have relatively abundant IRP. Body movements in limbless animals will inevitably involve both sides. As a consequence, motor commands to either side must be coordinated with those of the contralateral body part. In addition, when a snake or cyclostome is curled, the eye may receive visual information about ipsilateral as well as contralateral body parts. b Schematic of optic pathways in a vertebrate with lateralized visual fields and laterally placed forelimbs. Lizards, crocodilians, chameleons and mice exemplify animals that have no or very small proportions of IRP and lateralized visual fields. These animals rarely use forelimbs in the binocular visual field. When the forelimb is used in the lateral visual field, visual information about the forelimb will be integrated in the same hemisphere that receives somatosensory information and processes motor commands for that limb. c Schematic of optic pathways to the superior colliculus in a primate. In primates approximately $45 \%$ of RGCs project to targets on the same side.
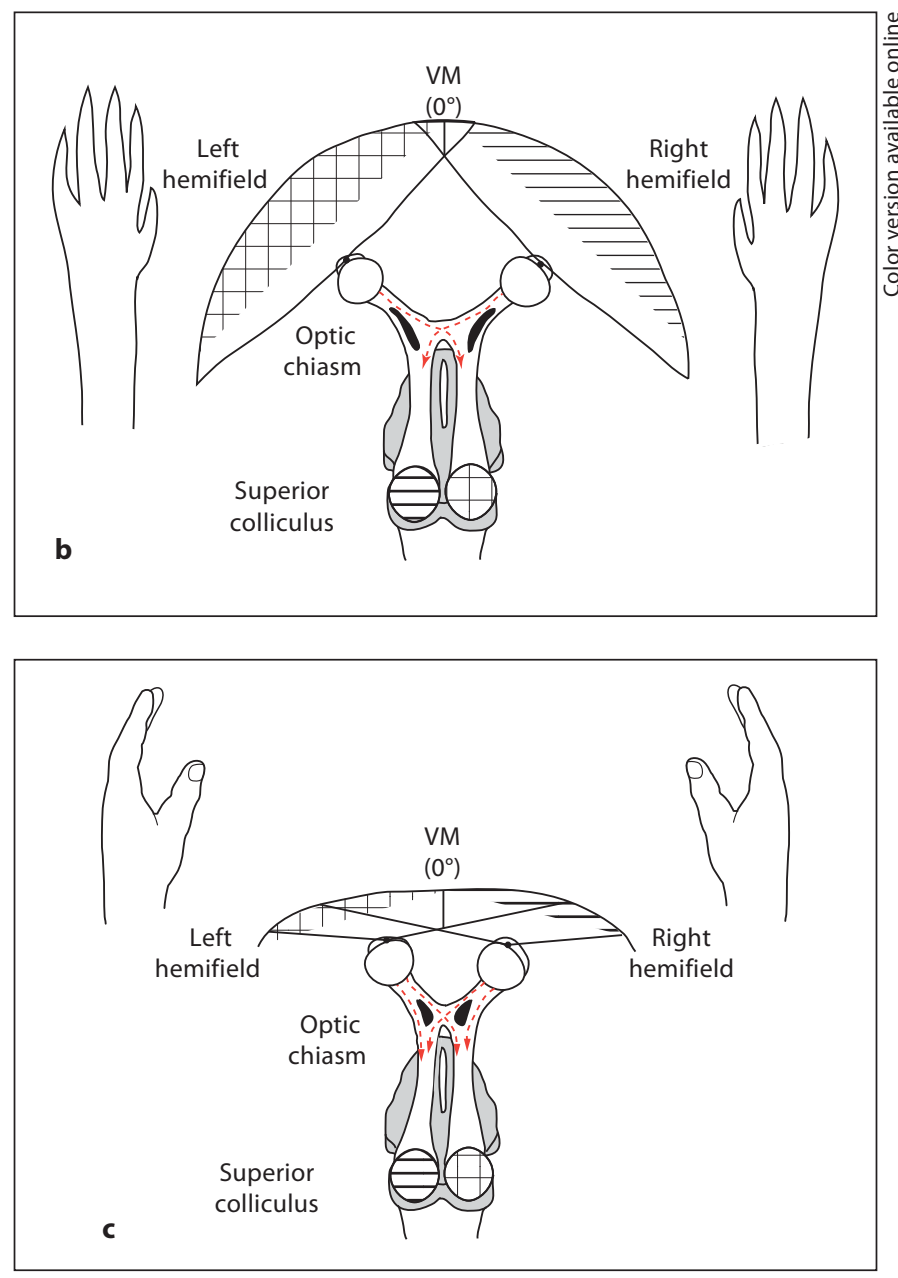

The combination of frontally directed eyes and abundant IRP from the temporal retina results in visual information about a limb's location in space being integrated in the same hemisphere that receives somatosensory information and processes motor commands for that limb. The figures are modified from Preuss [2007] based on Pettigrew et al. [1989]. VM =Visual field meridian. phins, since the front flipper can be supervised only with the ipsilateral eye. Bottlenose dolphins, Tursiops truncatus, display only crossed projections [Tarpley et al., 1994]. In species that often use forelimbs frontally (e.g. to capture prey, pick fruit, manipulate food, or to grip a branch during locomotion) evolutionary changes towards ipsilaterality in the lateral retina result in corresponding visual, motor, and somatosensory areas being localized in the same hemisphere (fig. 1c). As Berlucchi et al. [1971] suggested, one result will be shorter neural pathways. Moreover, in humans and tree-climbing primates, frontally directed eyes and IRP from the lateral retina result in shorter neural pathways in the visual cortex and motor area involved in visually guided maneuvers of the lower limbs.

\section{The $O C$ and Binocular Vision}

Many of the molecules and mechanisms involved in OC formation are evolutionarily conserved [Herrera and Mason, 2007]. The formation of the OC in the mouse, the most investigated mammal, takes place in the following order: pioneer axons from the dorsocentral retina navi- 
gate into the optic stalk and enter the hypothalamic area. The majority of these cross the midline. Subsequently, axons from the ventral temporal crescent arrive at the midline retina. These axons turn back to the ipsilateral brain hemisphere, while axons from the remainder of the retina cross the midline [Guillery et al., 1995; Mason and Sretavan, 1997]. In the third phase, all RGCs, regardless of origin, cross the midline [Sretavan, 1990; Herrera and Mason, 2007]. Transcription factors that play vital roles in the morphogenesis of the retina and the regionalization of the OC area have been identified, and alterations in transcription factors commonly cause abnormal OC phenotypes [Chung et al., 2004; Pak et al., 2004; Herrera and Garcia-Frigola, 2008]. Mutations in RGCs towards ipsilaterality have been frequently proposed as a mechanism facilitating binocular vision and acute depth perception, and the potential for stereoscopic depth perception is the most often cited advantage of binocularity in mammals [Williams et al., 2004; Heesy, 2008]. It is commonly suggested that animals with binocular vision use subtle differences between the images received by each eye to perceive stereoscopic depth [Heesy, 2009]. However, studies have failed to identify a cortical site primarily dedicated to stereoscopic depth perception [Parker, 2007]. Parker [2007] highlights a significant gap in knowledge concerning the stereo cues that are used by the parietal cortical regions during reaching and grasping movements.

Another potential advantage of binocular vision is enhanced light sensitivity, since it increases the likelihood of capturing light within the area of overlap [Pirenne, 1943; Williams et al., 2004; Heesy, 2008]. Binocularity is also proposed to improve contrast discrimination, defined as the ability to detect luminance differences in nearby objects or multiple parts of the same object [Pirenne, 1943; Campbell and Green, 1965; Heesy, 2009]. Many have proposed that an important function of hemidecussation is to obtain input from each retina and transmit the information to corresponding targets that are located more centrally. Stimuli from a point in the visual field received by each retina can be directed to the same location in the visual cortex, where two slightly differing images are integrated into a consistent three-dimensional representation [e.g. Jeffery and Erskine, 2005; Herrera and Mason, 2007]. The large overlap between the RVF and left visual field is a primate visual specialization [Cartmill, 1974]. A wide binocular field is related to high visual acuity, specialization of visual pathways in the brain, adaptations of the visuomotor system, and elaboration and differentiation of the visual cortex [Grantyn and
Moschovakis, 2004; Heesy, 2009]. It also correlates with the degree to which the bony orbits face in the same direction [Heesy, 2009]. Binocular vision is almost universal among vertebrates [Hughes, 1977]. All animals with two eyes have binocular vision, but the term is typically used only for animals that have a significant binocular overlap [Herrera and Garcia-Frigola, 2008]. Martin [2009] argued that stereopsis has been investigated in only a narrow range of species that have a moderately broad frontal binocular field, eyes that usually are widely spaced and forward-facing with parallel axes and conjugate movements, and that these are not typical traits of vertebrates. In the majority of vertebrates, eye position, eye movements, and binocular fields are quite different from hitherto investigated species [Martin, 2009].

\section{The EF Hypothesis and Visual Projections in Nonmammals}

In the following sections I review visual projections, eye direction, and motor behavior in nonmammal vertebrates. Supporting data are summarized in table 1.

\section{Fishes, Reptiles and Amphibians}

Cyclostomes, in general, exhibit IRP, leading Ward et al. [1995] to suggest that the ipsilateral contingent of fibers may be a phylogenetically primitive characteristic. The division of squamates that lost their limbs during evolution (snakes) possesses more abundant IRP than that of those with limbs (lizards) [Repérant et al., 1992]. When a cyclostome or snake (fig. 2) is curled, the eye may receive visual information about ipsilateral as well as contralateral body parts. Banihani [2010] proposed that locomotion and other body movements will inevitably involve both sides of the body in a limbless animal, i.e., motor commands to on one side of the body will also influence the contralateral body part. As a consequence, motor commands to either side must be coordinated with those of the contralateral body part. IRP in limbless animals may provide visual information that helps the brain to coordinate bilateral movements. Cyclostomes and snakes have relatively abundant IRP, which is in accordance with that premise, but why do nonteleost actinopterygians, such as sturgeon, possess extensive IRP [Repérant et al., 1982], and why are IRP frequent in cladistically primitive groups of teleosts and extremely rare in neoteleostans [Vonbartheld and Meyer, 1987; Medina et al., 1993; Ward et al., 1995]? Wilga and Lauder [1999] proposed that one of the most prominent features in the evo- 


\section{(1) Cyclostomes}

Extant representatives of these ancestral jawless vertebrates are hagfishes (myxinoids) and lampreys (petromyzontids). In spite of outward resemblances, they diverged early in vertebrate evolution [Forey and Janvier, 1993; Janvier, 2003].

VP: IRP have been demonstrated in the myxinoids Eptatretus burgeri [Kusunoki and Amemiya, 1983] and E. stouti [Wicht and Northcutt, 1990] and in the petromyzontiforms Lampetra fluviatilis [Vesselkin et al., 1980], L. planed [Demiguel et al., 1990], and Petromyzon marinus [Northcutt and Przybyls, 1973; Kennedy and Rubinson, 1977; Demiguel et al., 1990].

\section{(2) Chondrichthyans}

The cartilaginous fishes are separated into two major divisions, the elasmobranchii and the holocephali [Schaeffer and Williams, 1977]. Holocephali are rare, comprising only six living genera [Carroll, 1988]. The elasmobranchii include over 700 species and are divided into two superorders, the selachimorpha (sharks and dogfish) and the batioidimorpha (skates and rays) [Nelson, 1984]. VP: IRP are few in the spiny dogfish, Squalus acanthus

[Northcutt, 1979], the spotted dogfish, Scyliorhinus canicula [Repérant et al., 1986], and the shark Hemiscyllium plagiosum [Jen et al., 1983]. In the batoid Platyrhinoidis triseriata, numerous IRP have been demonstrated [Northcutt and Wathey, 1980].

\section{(3) Bony fish (Osteichthyes) \\ Ray-finned fishes \\ Subclass Brachiopterygii \\ VP: In Polypterus senegalus, IRP have been shown in a single hypothalamic site, the anterior portion of the optic tectum, two of five thalamic visual centers, and in one of three pretectal centers [Repérant et al., 1981].}

The sturgeon, Acipenser güldenstädti

VP: Extensive IRP are present in all primary visual centers that receive a contralateral afferent supply [Repérant et al., 1982].

\section{Subclass Actinopterygii}

The subdivision Teleostei (infraclass Neopterygii and division Halecostomi) is the most important radiation with more than 20,000 species [Nelson, 1984].

VP: IRP are less frequently described in Teleostei compared to other Actinopterygii. IRP are more frequent in cladistically primitive groups of Teleostei and extremely rare in neoteleostans [Vonbartheld and Meyer, 1987; Medina et al., 1993; Ward et al., 1995].

\section{Lobe-finned fishes}

Subgroup of the sarcopterygians and thus a sister group of tetrapods. Include four living genera: the dipnoan lungfish (Neoceratodus, Lepidosiren, and Protopterus) and the crossopterygian coelacanth, Latimeria [Nelson, 1984; Carroll, 1988]. VP: In Neoceratodus fosteri, generally considered to be the most primitive of the extant lungfish, IRP has been demonstrated [Moy-Thomas, 1971; Northcutt and Wathey, 1980], while studies in lepidosirenid lungfish have not revealed IRP [Northcutt, 1977; Ward et al., 1995].

\section{(4) Amphibians}

They include the Caudata (salamanders), the Gymnophiona (caecilians, a group of burrowing, limbless amphibians), and the Anura (frogs and toads) [Noble, 1931].

VP: Older studies [Herrick, 1925, 1948] commonly describe decussation as total in the amphibian OC, but more recent experimental works report IRP [Guillery and Updyke, 1976; Repérant et al., 1978; Rettig and Roth, 1986; Ward et al., 1995]. In caudate amphibians, IRP seem to be established early in development [Rettig et al., 1981; Rettig 1988; Ward et al., 1995]. In anurans, IRP emerge at the culmination of metamorphosis [Fritzsch, 1990], roughly when the eyes shift to a more frontal location [Gaze, 1970].

\section{(5) Chelonians}

Modern turtles comprise 240 species [Bellairs, 1970] distributed among 12 families [Gaffney and Meylan, 1988].

VP: Of 12 species that have been examined by autoradiographic techniques, all but one, Trionyx cartilagineus, show IRP [Ward et al., 1995].

\section{(6) Rhyncocephalians}

This separate and rare order of reptilian can be found only on small islands close to New Zealand [Eisthen and Polese, 2006]. VP: A study in a single specimen of Sphenodon did not show IRP [Northcutt et al., 1974].

\section{(7) Squamates}

Snakes and the lizards form the two major divisions [Bellairs, 1970].

Snakes

VP: IRP are modest in the majority of squamates [Repérant et al., 1978]. IRP are regularly more extensive in snakes than in lizards [Repérant et al., 1992]. In two subterranean microphthalmic species, the boid Calabaria reinhardtii [Repérant et al., 1978] and the scolecophidian Typhlops vermicularis [Halpern, 1973], rudimentary eyes are associated with extensive IRP.

Lizards

VP: In the agamid Uromastix acanthinurus [Repérant et al., 1978] and in Chameleo chamaeleon [Bennis et al., 1994] IRP are entirely absent.

\section{(8) Crocodilians}

VP: One (Caiman sclerops) of seven species has been investigated. Autoradiography did not reveal IRP [Repérant, 1975].

\section{(9) Birds}

VP: Most data on ipsilaterality are derived from chickens and pigeons [Remy and Gunturkun, 1991; Ward et al., 1995].

\section{(10) Monotremes}

Mammals that lay eggs.

VP: Studies are scarce [e.g. Campbell and Hayhow, 1971, 1972] and show few IRP. 
Table 1 (continued)

\section{(11) Marsupials}

Extant marsupials comprise approximately 250 species [Matthews, 1971]. Australian marsupials are often divided into two main groups: Diprodontia, species with two incisors in the lower jaw, includes possums, gliders, kangaroos, wombats, and the koala. The remaining species belong to several orders which often are grouped together as the polypropodonts [Harman et al., 1990]. Due to unique morphological and other characteristics, the honey possum, Tarsipes rostratus, is classified as the single representative of a diprodont superfamily, Tarsipedoidea, family Tarsipedidae [Kirsch and Calaby, 1977].

VP: The pattern of retinal projections differ somewhat in the North American opossum, Didelphys virginiana, and the South American Marmosa mitis, but in both species, bilateral projections have been revealed [Royce et al., 1976]. The retinal projections of investigated Australian marsupials [Harman et al., 1990] are generally similar, reporting retinal projections to seven targets, and of these, only one nucleus shows an exclusively contralateral supply [Sanderson et al., 1987; Ward et al., 1995]. The pattern of retinal input to the dLGN is more variable [Harman et al., 1990]. An extensive overlap of visual projections in the dLNG is seen in the polypropodont family Dasuridae. In most diprodonts, the dLGN display terminal banding and segregation of input from the right and left eye, but with a notable difference in two species, the feather-tailed glider, Acrobates pygmaeus, and the honey possum, Tarsipes rostratus, which both display extensive overlap from the two eyes in the dLGN, and accordingly small monocular segments (e.g. $12 \%$ in the honey possum) [Harman et al., 1990]. Similarly, an arboreal South American opossum, Marmosa mitis, has a small monocular segment (17\%) [Royce et al., 1976]. Ground-dwelling and herbivorous wombats [Triggs, 1996] have a large monocular segment, $66 \%$ of the dLGN, while other examined marsupial species have monocular segments between 25 and 35\% [Harman et al., 1990].

lution of ray-finned fishes is the change in pectoral fin position and function. In most teleosts the pectoral fins extend laterally in a transverse plane and are located in a somewhat dorsal position on the side of the body [Rosen, 1982]. However, in the plesiomorphs, such as the sturgeon, the pectoral fins extend laterally from a ventral insertion on the pectoral girdle and are held in a generally horizontal orientation [Bemis et al., 1997; Wilga and Lauder, 1999]. As a result, the pectoral fins of sturgeon are relatively immobile, and there is typically no observable change in pectoral fin position during tail beats, while many teleosts utilize oscillatory motions of pectoral fins to generate propulsive forces [Wilga and Lauder, 1999]. Lepidosirenid lungfish also display complex movements of the pectoral fins, such as using them to raise the anterior part of the body and in conveying food into the mouth [Janvier, 2003]. Studies of lepidosirenid lungfish have not revealed ipsilateral visual projections [Northcutt, 1977; Ward et al., 1995]. In the elasmobranchii, Squalus exemplifies a fish in which visual supervision is restricted to the ipsilateral forelimb (pectoral fin), thus its low numbers of IRP [Northcutt, 1979] are in accordance with the EF hypothesis. However, the phylogenetically more advanced batoid Platyrhinoidis shows numerous ipsilateral projections [Northcutt and Wathey, 1980; Ward et al., 1995]. Ebbesson and Meyer [1980] suggested that the retinal projections in the batoid guitarfish, Rhinobatidae, differ from those of other elasmobranch species in that some parts of the body will be included in the visual field, since it has a flat body shape. However, whether the guitarfish eye and body morphology allows supervision of contralateral body movements remains to be studied.

Ward et al. [1995] suggested that the considerable interspecific variation in the visual projections of the turtles (Testudines) cannot be explained in terms of taxonomic position or of mode of life, and constitutes a notable inconsistency in the NGM law. Among the investigated turtles, the only species lacking IRP, Trionyx cartilaginous, has eyes notably more frontally placed and a larger binocular field than does Chinemys, in which the ipsilateral projections are among the most extensive [Hergueta et al., 1992].

RGCs project bilaterally with a contralateral dominance in most lizards, and projections are, on the whole, contralateral in crocodilians and completely contralateral in chameleons and uromastix lizards [Burns and Goodman, 1967; Repérant, 1975; Bennis et al., 1994; Tarpley et al., 1994; Ward et al., 1995; Derobert et al., 1999; Bruce, 2009]. Since these animals have little frontal use for their forelimbs, this is consistent with the EF hypothesis. In amphibians, the pattern is variable. Plethodontid salamanders have substantial numbers of IRPs [Wiggers, 1999; Dicke and Roth, 2009]. Plethodontid salamanders, in particular tropical climbing salamanders, Bolitoglossa, comprising $50 \%$ of extant salamanders, have developed a peculiar feeding apparatus specialized for tongue protraction [Roth and Schmidt, 1993]. Wiggers et al. [1995] suggested that the substantial number of IRPs in Bolitoglossa is the basis for a fast computation of object distance. Notably, the projectile tongue of the Bolitoglossa is combined with a more frontal eye position relative to other salamanders [Roth and Schmidt, 1993]. The African clawed frog, Xenopus laevis, has only crossed projections until metamorphosis, when it develops binocularity, ipsilateral connections, and forelimbs with claws [Gaze, 1970; Fritzsch, 1990; Jeffery and Erskine, 2005]. Carreno 
Fig. 2. When a snake is curled each eye may receive visual information about ipsilateral as well as contralateral body parts. In addition, body movements in eel- and snake-like animals (cyclostomes and caecilians) unavoidably engage both sides of the body, i.e., the left and right side must move in coordination. (Photo: Kveta Källmén).

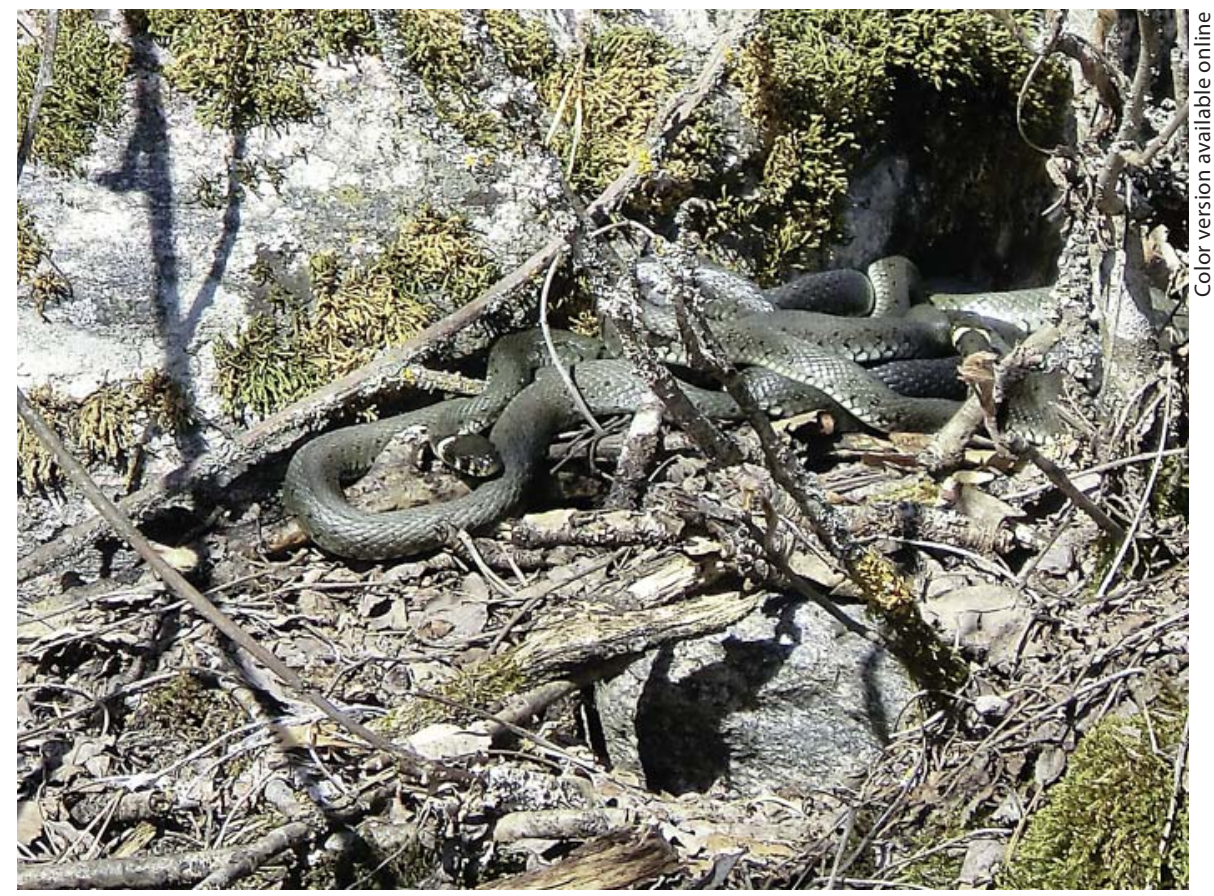

and Nishikawa et al. [2010] showed that prior to capturing prey, the forelimbs of $X$. laevis are held in a forward flexed position, with each forelimb positioned in front of the head. During prey capture, the forelimbs are extended and used to capture prey and move it to the mouth. In a third amphibian group, the limbless caecilian Ichthyophis kohtaoensis displays contralateral retinal projections as well as IRP [Himstedt and Manteuffel, 1985].

In marsupials, the pattern of retinal input to the dorsal lateral geniculate nucleus (dLGN) is variable and has been extensively studied [Royce et al., 1976; Harman et al., 1990] (table 1). Abundant overlap of visual projections in the dLGN will be largely analogous to high proportions of IRP. Two species of diprodonts with an arboreal lifestyle, the feather-tailed glider, Acrobates pygmaeus, and the honey possum, Tarsipes rostratus, display extensive overlap in the dLGN from the eyes [Harman et al., 1990]. Similarly, an arboreal South American opossum, Marmosa mitis, displays extensive overlap in the dLGN [Royce et al., 1976]. Ground-dwelling herbivorous wombats are reported to have the least overlap [Triggs, 1996], while other investigated marsupials fall between these extremes [Sanderson et al., 1987].

\section{Birds}

Adult birds seem to have no or very few IRP [Remy and Gunturkun, 1991; Ward et al., 1995]. In bird embry- os an important ipsilateral projection develops that is greatly reduced just before hatching [Thanos and Bonhoeffer, 1984]. Since birds are descendants of tetrapod reptiles, their ontogeny might reflect the phylogenic development of birds, i.e. bird predecessors may have had more extensive ipsilateral projections. Avian predecessors had very long forelimbs, e.g., in Archaeopteryx the forelimb is $120-140 \%$ of the hindlimb length [Gauthier, 1986], which may have been compatible with frontal forelimb use. Birds do not display hemidecussation of retinal axons at the level of the OC, but they do show an interhemispheric crossing of visual fibers at the thalamotelencephalic level [Remy and Gunturkun, 1991]. The nucleus opticus principalis thalami is the equivalent structure to the lateral geniculate of mammals and receives a group of contralateral retinal fibers. This nucleus in turn projects bilaterally to the visual wulst, the equivalent avian structure of the V1 cortex. Thus, the bird primary visual cortex receives an IRP via the nucleus opticus principalis thalami [Remy and Gunturkun, 1991; Martin, 2009]. In particular, owls have a high degree of IRP [Pettigrew, 1986a]. Owls exhibit double decussation rather than the partial decussation of mammals. Pettigrew [1986a] suggested that owls have developed an elaborate neural substrate for binocular vision, and that most of the features described for the mammalian binocular visual pathway have a counterpart in the 
binocular visual pathway of the owl. Martin [2009] reviewed binocular vision in birds and proposed that maximum binocular field width across most avian taxa ranges from $15^{\circ}$ to $30^{\circ}$. In owls, maximum binocular field widths are typically almost twice this. The hypothesis that binocularity inevitably results in stereopsis in birds has been questioned [Davies and Green, 1994; McFadden, 1994]. Davies and Green [1994] suggested that too much time is required, especially during critical rapid flight maneuvers, to reach a sufficient level of accuracy in estimating depth through stereopsis. In filter-feeding ducks, the frontal binocular overlap is less than $10 \%$, and in woodcock it is around 5\%. In spite of this, woodcock are capable of rapid flight in complex habitats such as woodland [Martin, 2009]. Owls probably have the widest binocular fields of any avian species, but the binocular fields are narrower than the impression gained from casual observation and are not at the level of those of primates [Martin, 2009]. Since owls do not use wings for manipulation of objects, in the frontal position, their elaborate neural substrate for binocular vision appears to be at odds with the EF hypothesis. The decussation and binocular vision of owls may in theory improve eye-lower-limb coordination, which may have selective value in predation. Raptors normally take prey with their feet, approaching the target with feet brought up into the visual field just prior to capture [Martin and Katzir, 1999]. Several owl species have been observed foraging on foot [Johnsgard, 1988; Taylor, 1994; McMillian, 1998]; however, foraging on foot is common in many bird species. Owls seem to be an outlier group with respect to the EF hypothesis. Their acute vision and relatively unique hunting habits may be involved. Martin [2009] suggested that the primary function of binocular vision in birds is to extract information used in control of bill and foot position and the timing of opening the bill or feet, e.g. when pecking, lunging, taking prey, or feeding young birds.

\section{Discussion}

This EF hypothesis provides a novel, or complementary, approach to the question of why vertebrate species show differing proportions of IRP. In essence, it suggests that evolutionary processes may switch the direction of RGCs so that their axons may or may not cross the midline in the OC. An evolutionary change from the ancestral condition (with several IRP) towards reduced IRP proportions may be of adaptive value in animals that exclusively or almost exclusively use the forelimbs in a lateral position, since increased contralateral IRP will result in additional visual information to the hemisphere that processes motor commands to the limb (fig. 1b). Evolutionary changes towards increased IRP result in shorter neural pathways and thus improve limb coordination in animals such as primates that regularly use the forelimbs frontally (fig. 1c). Evolutionary change in RGCs in limbless species is likely to influence supervision of body movements differently. When a snake is curled each eye may receive visual information about ipsilateral as well as contralateral body parts (fig. 2). In addition, body movements in eel- and snake-like animals inevitably involve both sides of the body, i.e., the left and right side must move in coordination. This might explain why a high proportion of IRP have been demonstrated in the so-called ancestral condition, e.g. in eel-like cyclostomes, and why phylogenetically diverse animal groups such as snakes and caecilians also display high proportions of IRP (fig. 1a). A strength of the hypothesis is that primates, an animal group characterized by superior eye-hand coordination, possess the most extensive IRP. Cats use visually guided forelimb movements during prey capture to a large extent [Hughes, 1977] and also display high proportions of IRP [Herrera and Mason, 2007]. An evolutionary change towards increased IRP involving RGCs in the nasal retina would give the contrary result with regard to visually guided movements, i.e. increase the distance between coworking visual and motor areas. In vertebrates, uncrossed projections arise exclusively from the temporal retina [Jeffery and Erskine, 2005], which is accommodated by the EF hypothesis. In mice, the number of uncrossed projections is low, and the corresponding RGCs are located in a crescent-shaped area bordering the inferior temporal retina [Drager and Olsen, 1980]. Due to the anatomy of the snout in rodents [Hughes, 1977], it is likely that the only space in which the contralateral paw might be viewed is the upper quadrant of the visual field, which corresponds to the inferior temporal retina. Visual pathways to the suprachiasmatic nucleus of the hypothalamus and pretectum are unlikely to be involved in EF coordination, which may explain the many divergent functional and evolutionary characteristics of these 'non-image-forming' visual pathways [Magnin et al., 1989]. The EF hypothesis postulates no direct association with a nocturnal, euryphotic, diurnal, or predatory mode of life, factors that, at least in nonmammals, have little or no association with the degree of IRP. The EF hypothesis might explain why IRP develop in X. lae- 
vis, at metamorphosis simultaneously with their dexterous forelimbs. An ambiguity is that in mammals the visual thalamotelencephalic projections are uncrossed but that is not the case in many nonmammalian vertebrates [Heesy, 2009]. The elaborate neural substrate for binocular vision in owls cannot be explained in light of the EF hypothesis; on the other hand, the association between binocular vision and depth perception in birds has been questioned [Davies and Green, 1994; McFadden, 1994].

A key role of binocular vision in vertebrates may be to provide the brain with accurate information about the position and timing of crucial body parts, such as digits/ hands, forelimbs, bill, projectile tongue, or feet. An example may be the binocular field of artiodactyls and perissodactyls that is extended not in width but downwards along a narrow strip in the midsagittal plane to deal with ground near the feet [Pisa, 1939; Hughes, 1977]. Similarly, the unusual vertical orientation of the visual streak in the retina of the two-toed sloth [Andrade-da-Costa et al., 1989; Harman et al., 1990] may be linked to eye-limb coordination, since this species has the habit of hanging upside down.

Dexterity, in its strictest sense, reflects fine motor abilities. Under such a definition rodents are far more dexterous than felids [Whishaw et al., 1998]. However, it is not dexterity, but visually guided forelimb movements, dexterous or not, that would appear to correlate with a high degree of IRP. In accordance with this, cats, with high proportions of IRP [Herrera and Mason, 2007], are known to use visually guided forelimb movements during prey capture [Hughes, 1977], while rodents, animals with few IRP, can use fine-motor movements to manipulate food items without visual feedback [Whishaw et al., 1998]. In addition, rodents use olfaction for food identification while most primates use vision [Whishaw and Tomie, 1989]. Megabats use their long forelimbs (wings with a clawed thumb) in manual tasks such as picking and manipulating fruit [Vandoros and Dumont, 2004], and, since they have a high degree of binocular vision [Pettigrew, 1986b], such tasks may be performed under strictly visual control. Thus primate-like visual specialization in megabats, such as a highly elaborated visual cortex [Rosa et al., 1993] and a similar pattern of decussation in the retina [Pettigrew, 1986b; Pettigrew et al., 2008], conforms to the EF hypothesis. Among investigated marsupials, three arboreal species have the smallest monocular segment in the dLGN (analogous to a high proportion of IRP) [Royce et al., 1976; Harman et al., 1990], while the ground-dwelling and herbivorous wom- bats have the largest monocular segment in the dLGN [Sanderson et al., 1987], indicating a low proportion of IRP.

Ross and Martin [2007] meant that dexterity and eyehand coordination are important traits to distinguish primates. Fossil evidence implies that the first true primates emerged approximately 55 million years ago as specialized graspers [Bloch and Boyer, 2002]. Stem primates may have evolved manual grasping abilities and other specializations to feed on flowers, nectar, and leaves in the distal branches of trees [Bloch and Boyer, 2002]. These authors put forward that manual grasping abilities of primates evolved prior to their visual specialization. The hypothesis presented here implies that manual grasping abilities evolved in direct association with primate visual specializations through a common evolutionary mechanism, i.e. that increased IRP were selected for in species that regularly use the forelimbs in the frontal visual field. Improved eye-lower-limb coordination could have added to the selective value in tree-climbing primates.

It is difficult to draw firm conclusions, since acute depth perception, dexterity, binocular vision, and frontal forelimb use are overlapping traits in many animal groups. Much data on ipsilaterality is older and may be based on the law of NGM rather than direct studies of axon routing in the OC [Herrera, 2009, pers. commun.]. Iwaniuk et al. [1999] developed a list of brain sizes and scores for dexterity but found no significant correlation between forelimb dexterity and overall brain size in carnivores. They proposed that alterations in forelimb dexterity can be achieved through development of the connectivity among neural structures rather than through gross changes in the morphology of the central nervous system. A similar list with scores for EF coordination and accurate data on the degree of ipsilaterality in the OC in an assortment of nonmammal and mammal species could be of value to further validate the EF hypothesis. Studies of locomotion, feeding behavior, and EF coordination in the turtles T. cartilaginous and Chinemys would also be of interest. In addition, the assumption that fish species such as sturgeon, with relatively immobile pectoral fins, have higher proportions of IRP relative to fish with bilaterally self-governing fin movements, may be tested empirically. Anatomical, neurophysiological, phylogenetic, ontogenetic, and ecological data suggest that evolutionary changes in the proportions of ipsilateral visual connections in the OC may have selective value with respect to $\mathrm{EF}$ coordination. 


\section{Acknowledgements}

I thank two anonymous reviewers for valuable comments and suggestions. Prof. Graham D. Martin, University of Birmingham, Prof. Per Alf Brodal, University of Oslo, Eloise Herrera, $\mathrm{PhD}$, Instituto de Neurociencias de Alicante, and Prof. Glen Jeffery, University College London read and gave valuable comments on early versions of the manuscript. I thank Ms. Kathleen
Hills and Dr. Alan Pike at The Lucidus Consultancy for engaged and skilful help with the English language and editorial comments, and Associate Research Prof. Todd Preuss, Emory University Atlanta, Ga., for his kind permission to use and modify the figure from Preuss [2007] based on Pettigrew et al. [1989]. I also thank Maria Bergman, Department of Medical Photography, Örebro University Hospital, for help with the production of the figure.

\section{References}

-Andrade-da-Costa BLS, Pessoa VF, Bousfield JD, Clarke RJ (1989): Ganglion cell size and distribution in the retina of the two-toed sloth (Choloepus didactylus L.). Braz J Med Biol Res 22:233-236.

-Aziz-Zadeh L, Iacoboni M, Zaidel E (2006): Hemispheric sensitivity to body stimuli in simple reaction time. Exp Brain Res 170:116121.

Banihani SM (2010): Crossing of neuronal pathways: is it a response to the occurrence of separated parts for the body (limbs, eyes, etc.) during evolution? Med Hypotheses 74: 741-745.

Bellairs A (1970): The Life of Reptiles. New York, Universe Books.

Bemis WE, Findeis EK, Grande L (1997): An overview of Acipenseriformes. Environ Biol Fishes 48:25-72.

Bennis M, Reperant J, Rio JP, Ward R (1994): An experimental re-evaluation of the primary visual system of the European chameleon, Chamaeleo chameleon. Brain Behav Evol 43 : 173-188.

- Berlucchi G, Heron W, Hyman R, Rizzolat G, Umilta C (1971): Simple reactions times of ipsilateral and contralateral hand to lateralized visual stimuli. Brain 94:419-430.

Bloch JI, Boyer DM (2002): Grasping primate origins. Science 298:1606-1610.

Bruce LL (2009): Evolution of nervous system in reptiles; in Kaas JH (ed): Evolutionary Neuroscience. Oxford, Elsevier Science.

- Burns AH, Goodman DC (1967): Retinofugal projections of Caiman sklerops. Exp Neurol 18:105-115.

Campbell CB, Hayhow WR (1971): Primary optic pathways in the echidna, Tachyglossus aculeatus - experimental degeneration study. J Comp Neurol 143:119-136.

-Campbell CB, Hayhow WR (1972): Primary optic pathways in the duckbill platypus, $\mathrm{Or}$ nithorynchus anatinus: an experimental degeneration study. J Comp Neurol 145:195208.

Campbell FW, Green DG (1965): Monocular versus binocular visual acuity. Nature 208:191192.

-Carreno CA, Nishikawa KC (2010): Aquatic feeding in pipid frogs: the use of suction fo prey capture. J Exp Biol 213:2001-2008.
Carroll RL (1988): Vertebrate Paleontology and Evolution. New York, Freeman.

Cartmill M (1974): Rethinking primate origins. Science 184:436-443.

Chung KY, Leung KM, Lin CC, Tam KC, Hao YL, Taylor JS, Chan SO (2004): Regionally specific expression of $\mathrm{L} 1$ and sialylated NCAM in the retinofugal pathway of mouse embryos. J Comp Neurol 471:482-498.

Davies MNO, Green PR (1994): Multiple sources of depth information: an ecological approach; in Davies MNO, Green PR (eds): Perception and Motor Control in Birds: An Ecological Approach. Berlin, Springer, pp 339356.

Demiguel E, Rodicio MC, Anadon R (1990): Organization of the visual system in larval lampreys: an HRP study. J Comp Neurol 302: 529-542.

Derobert Y, Medina M, Rio JP, Ward R, Reperant J, Marchand MJ, Miceli D (1999): Retinal projections in two crocodilian species, Caiman crocodilus and Crocodylus niloticus. Anat Embryol (Berl) 200:175-191.

Dicke U, Roth G (2009): The evolution of the amphibian nervous system; in Evolutionary Neuroscience. Oxford, Elsevier Science.

Drager UC, Olsen JF (1980): Origins of crossed and uncrossed retinal projections in pigmented and albino mice. J Comp Neurol 191: 383-412.

Ebbesson SOE, Meyer DL (1980): Visual system of the guitar fish (Rhinobatos productus). Cell Tissue Res 206:243-250.

Eisthen HL, Polese G (2006): Evolution of vertebrate olfactory subsystems; in Kaas JH (ed): Evolution of Nervous Systems: Non-Mammalian Vertebrates. Amsterdam, Elsevier, vol 2, pp 355-406.

Elliot Smith G (1928): The new vision. Nature 121:680-681.

Fisk JD, Goodale MA (1985): The organization of eye and limb movements during unrestricted reaching to targets in contralateral and ipsilateral visual space. Exp Brain Res 60:159-178.

Forey P, Janvier P (1993): Agnathans and the origin of jawed vertebrates. Nature 361:129134.

Fritzsch B (1990): The evolution of metamorphosis in amphibians. J Neurobiol 21:10111021.
Fukuda Y, Sawai H, Watanabe M, Wakakuwa K, Morigiwa K (1989): Nasotemporal overlap of crossed and uncrossed retinal ganglion cell projections in the Japanese monkey (Macaca fuscata). J Neurosci 9:2353-2373.

Gaffney ES, Meylan PA (1988): A phylogeny of turtles; in Benton MJ (ed): The Phylogeny and Classification of the Tetrapods, vol 1: Amphibians, Reptiles, Birds. Systematics Association Special Volume 35A. Oxford, Clarendon Press, pp 157-219.

Gauthier J (1986): Saurischian monophyly and the origin of birds; in Padian K (ed): The Origin of Birds and the Evolution of Flight. California Academy of Sciences, San Francisco, pp 1-55.

Gaze RM (1970): The Formation of Nerve Connections. London, Medical Books.

Grantyn AA, Moschovakis AK (2004): Structure-function relationships in the superior colliculus of higher mammals; in Hall W, Moschovakis A (eds): The Superior Colliculus: New Approaches for Studying Sensorimotor Integration. New York, CRC Press, pp 107-145.

Guillery RW, Mason CA, Taylor JS (1995): Developmental determinants at the mammalian optic chiasm. J Neurosci 15:4727-4737.

Guillery RW, Updyke BV (1976): Retinofugal pathways in normal and albino axolotls. Brain Res 109:235-244.

Halpern M (1973): Retinal projections in blind snakes. Science 182:390-391.

- Harman AM, Coleman LA, Beazley LD (1990): Retinofugal projections in a marsupial, Tarsipes rostratus (honey possum). Brain Behav Evol 36:30-38.

Harris W (1904): Binocular and stereoscopic vision in man and other vertebrates, with its relation to the decussation of the optic nerves, the ocular movements, and the pupil reflex. Brain 27:107-147.

Heesy CP (2008): Ecomorphology of orbit orientation and the adaptive significance of binocular vision in primates and other mammals. Brain Behav Evol 71:54-67.

Heesy CP (2009): Seeing in stereo: the ecology and evolution of primate binocular vision and stereopsis. Evol Anthropol 18:21-35.

Henderson Z (1985): Distribution of ganglioncells in the retina of adult pigmented ferret. Brain Res 358:221-228. 
-Hergueta S, Ward R, Lemire M, Rio JP, Repérant J, Weidner C (1992): Overlapping visual fields and ipsilateral retinal projections in turtles. Brain Res Bull 29:427-433.

- Herrera E, Garcia-Frigola C (2008): Genetics and development of the optic chiasm. Front Biosci 13:1646-1653.

Herrera E, Mason CA (2007): The evolution of crossed and uncrossed retinal pathways in mammals; in Krubitzer L, Kaas J (eds): Evolution of Nervous Systems: Mammals. Oxford, Elsevier, vol 3, pp 307-317.

Herrick CJ (1925): The amphibian forebrain. III. The optic tracts and centers of Amblystoma and the frog. J Comp Neurol 39:433-489.

Herrick CJ (1948): The Brain of the Tiger Salamander, Ambystoma tigrinum. Chicago, University of Chicago Press.

Himstedt W, Manteuffel G (1985): Retinal projections in the caecilian Ichthyophis kohtaoensis (Amphibia, Gymnophiona). Cell Tissue Res 239:689-692.

Hughes A (1977): The topography of vision in mammals of contrasting life styles; in Crescitelli F (ed): Handbook of Sensory Physiology: The Visual System in Vertebrates. Berlin, Springer, vol 7/5 A, pp 613756.

-Iwaniuk AN, Pellis SM, Whishaw IQ (1999): Brain size is not correlated with forelimb dexterity in fissiped carnivores (Carnivora): a comparative test of the principle of proper mass. Brain Behav Evol 54:167-180.

Janvier P (2003): Early Vertebrates. Oxford, Oxford University Press.

Jeffery G, Erskine L (2005): Variations in the architecture and development of the vertebrate optic chiasm. Prog Retin Eye Res 24:721-753.

Jen LS, So KF, Yew DT, Lee M (1983): An autoradiographic study of the retinofugal projections in the shark, Hemiscyllium plagiosum. Brain Res 274:135-139.

Johnsgard PA (1988): North American Owls: Biology and Natural History. Washington, Smithsonian Institution Press.

Kennedy MC, Rubinson K (1977): Retinal projections in larval, transforming and adult sea lamprey, Petromyzon marinus. J Comp Neurol 171:465-479.

Kirsch JAW, Calaby JH (1977): The species of living marsupials. An annotated list; in Stonehouse B, Gilmore D (eds): The Biology of Marsupials. London, Macmillan, pp 9-26.

Kusunoki T, Amemiya F (1983): Retinal projections in the hagfish, Eptatretus burgeri. Brain Res 262:295-298.

Le Gros Clarke WE (1934): The Early Forerunners of Man. London, Tindall \& Cox.

-Magnin M, Cooper HM, Mick G (1989): Retinohypothalamic pathway: a breach in the law of Newton-Muller-Gudden? Brain Res 488: 390-397.

Martin GR (2009): What is binocular vision for? A birds' eye view. J Vis 9:14.1-14.19.
Martin GR, Katzir G (1999): Visual fields in short-toed eagles, Circaetus gallicus (Accipitridae), and the function of binocularity in birds. Brain Behav Evol 53:55-66.

Mason CA, Sretavan DW (1997): Glia, neurons, and axon pathfinding during optic chiasm development. Curr Opin Neurobiol 7:647653.

Matthews LH (1971): The Life of Mammals. London, Weidenfeld \& Nicholson.

McFadden SA (1994): Binocular depth perception; in Davies MNO, Green PR (eds): Perception and Motor Control in Birds: An Ecological Approach. Berlin, Springer, pp 54-73.

McMillian MA (1998): Foot-hunting behavior by a great horned owl. Florida Field Nat 26:9193.

Medina M, Reperant J, Ward R, Rio JP, Lemire M (1993): The primary visual system of flatfish: an evolutionary perspective. Anat Embryol (Berl) 187:167-191.

-Morgan JE, Henderson Z, Thompson ID (1987): Retinal decussation patterns in pigmented and albino ferrets. Neuroscience 20:519-535.

Moy-Thomas JA (1971): Palaeozoic Fishes. London, Chapman \& Hall.

Nelson JS (1984): Fishes of the World, ed 2. New York, Wiley.

Newton I (1931): Opticks: Or a Treatise of the Reflections, Refractions, Inflections and Colours of Light (1st ed 1704). London, Bell.

Noble GK (1931): The Biology of the Amphibia. New York, McGraw-Hill.

-Northcutt RG (1977): Retinofugal projections in the lepidosirenid lungfishes. J Comp Neurol 174:553-574

Northcutt RG (1979): Retinofugal pathways in fetal and adult spiny dogfish, Squalus-acanthias. Brain Res 162:219-230.

Northcutt RG, Braford MR, Landreth GE (1974): Retinal projections in the tuatara Sphenodon punctatus: an autoradiographic study. Anat Rec 178:428.

Northcutt RG, Przybyls RJ (1973): Retinal projections in the lamprey Petromyzon marinus L. Anat Rec 150:400.

Northcutt RG, Wathey JC (1980): Guitarfish possess ipsilateral as well as contralateral retinofugal projections. Neurosci Lett 20:237242.

Pak W, Hindges R, Lim YS, Pfaff SL, O'Leary DD (2004): Magnitude of binocular vision controlled by islet-2 repression of a genetic program that specifies laterality of retinal axon pathfinding. Cell 119:567-578.

Parker AJ (2007): Binocular depth perception and the cerebral cortex. Nat Rev Neurosci 8 : 379-391.

Petros TJ, Rebsam A, Mason CA (2008): Retinal axon growth at the optic chiasm: to cross or not to cross. Annu Rev Neurosci 31:295-315.

Pettigrew JD (1986a): The evolution of binocular vision; in Pettigrew JD, Sanderson KJ, Levick WR (eds): Visual Neuroscience. Cambridge, Cambridge University Press.
Pettigrew JD (1986b): Flying primates? Megabats have the advanced pathway from eye to midbrain. Science 231:1304-1306.

- Pettigrew JD, Jamieson BG, Robson SK, Hall LS, McAnally KI, Cooper HM (1989): Phylogenetic relations between microbats, megabats and primates (Mammalia: Chiroptera and Primates). Philos Trans R Soc Lond B Biol Sci 325:489-559.

- Pettigrew JD, Maseko BC, Manger PR (2008): Primate-like retinotectal decussation in an echolocating megabat, Rousettus aegyptiacus. Neuroscience 153:226-231.

Pirenne MH (1943): Binocular and uniocular threshold of vision. Nature Land 152:698699.

Pisa A (1939): Über den binokularen Gesichtsraum bei Haustieren. Arch Ophthalmol 140: $1-54$.

Polyak S (1957): Investigation of the visual pathways and centers during Classical Antiquity, the Middle Ages, and the early period of the modern scientific Era; in Klüver H (ed): The Vertebrate Visual System. Chicago, University of Chicago Press, pp 113-115.

Preuss TM (2007): Evolutionary specializations of primate brain systems; in Ravosa $\mathrm{M}, \mathrm{Da}$ gosto M (eds): Primate Origins: Adaptations and Evolution. New York, Springer Science+Business Media, pp 625-675.

Ramon Y Cajal S (1972): Nerfs, chiasma et bandelenes optiques; in Histologie du Système de l'Homme et des Vertébrés. Madrid, Consejo Superior de Investigaciones Científicas, vol 2, pp 368-380.

Remy M, Gunturkun O (1991): Retinal afferents to the tectum opticum and the nucleus opticus principalis thalami in the pigeon. J Comp Neurol 305:57-70.

- Repérant J (1975): Nouvelles données sur les projections retiniennes chez Caiman sclerops: étude radioautographique. CR Acad Sci 280: 2881-2884.

- Repérant J, Miceli D, Rio JP, Peyrichoux J, Pierre J, Kirpitchnikova E (1986): The anatomical organization of retinal projections in the shark Scyliorhinus canicula with special reference to the evolution of the selachian primary visual system. Brain Res Rev 11:227248

-Repérant J, Rio JP, Miceli D, Amouzou M, Peyrichoux J (1981): The retinofugal pathways in the primitive African bony fish Polypterus senegalus (Cuvier, 1829). Brain Res 217:225243

Repérant J, Rio JP, Miceli D, Lemire M (1978): A radioautographic study of retinal projections in type I and type II lizards. Brain Res 142:401-411.

Repérant J, Rio JP, Ward R, Hergueta S, Miceli D, Lemire M (1992): Comparative analysis of the primary visual system of reptiles; in Gans C, Ulinski PS (eds): Biology of the Reptilia. Chicago, University of Chicago Press, vol 17: Neurology C: Sensorimotor Integration, pp 175-240. 
Repérant J, Vesselkin NP, Ermakova TV, Rustamov EK, Rio JP, Palatnikov GK, Peyrichoux J, Kasimov RV (1982): The retinofugal pathways in a primitive actinopterygian, the chondrostean Acipenser güldenstädti. An experimental study using degeneration, radioautographic and HRP methods. Brain Res 251:1-23.

Rettig G (1988): Development of retinofugal neuropil areas in the brain of the alpine newt, Triturus alpestris. II. Topographic organization and formation of projections. Anatom Embryol 177:257-265.

-Rettig G, Fritzsch B, Himstedt W (1981): Development of retinofugal neuropil areas in the brain of the alpine newt, Triturus alpestris. Anatom Embryol 162:163-171.

- Rettig G, Roth G (1986): Retinofugal projections in salamanders of the family Plethodontidae. Cell Tissue Res 243:385-396.

Rosa MGP, Schmid LM, Krubitzer LA, Pettigrew JD (1993): Retinotopic organization of the primary visual cortex of flying foxes (Pteropus poliocephalus and Pteropus scapulatus). J Comp Neurol 335:55-72.

Rosen DE (1982): Teleostean interrelationships, morphological function and evolutionary inference. Am Zool 22:261-273.

Ross CF, Martin RD (2007): The role of vision in the origin and evolution of primates; in Preuss T, Kaas J (eds): Evolution of Nervous Systems: The Evolution of Primate Nervous Systems. Oxford, Elsevier, vol 4.

Roth G, Schmidt A (1993): The nervous system of Plethodontid salamanders: insight into the interplay between genome, organism, behavior and ecology. Herpetologica 49:185194.

Royce GJ, Ward JP, Harting JK (1976): Retinofugal pathways in two marsupials. J Comp Neurol 170:391-413.
Sanderson KJ, Nelson JE, Crewther DP, Crewther SG, Hammond VE (1987): Retinogeniculate patterns in diprotodont marsupials. Brain Behav Evol 30:22-42.

Schaeffer B, Williams M (1977): Relationship of fossil and living elasmobranchs. Am Zool 17: 293-302.

Soury J (1899): Entre-croisement partiel des nerfs optiques dans le chiasma; in Carre G, Naud C (eds): Système Nerveux Central. Chartres, Durand, pp 1440-1444.

Sretavan DW (1990): Specific routing of retinal ganglion cell axons at the mammalian optic chiasm during embryonic development. J Neurosci 10:1995-2007.

- Tarpley RJ, Gelderd JB, Bauserman S, Ridgway SH (1994): Dolphin peripheral visual pathway in chronic unilateral ocular atrophy: complete decussation apparent. J Morphol 222:91-102.

Taylor I (1994): Barn Owls: Predator-Prey Relationships and Conservation. Cambridge, Cambridge University Press.

Thanos S, Bonhoeffer F (1984): Development of the transient ipsilateral retinotectal projection in the chick embryo: a numerical fluorescence-microscopic analysis. J Comp Neurol 224:407-414.

Triggs B (1996): The Wombat: Common Wombats in Australia. Sydney, University of New South Wales Press.

-Vandoros JD, Dumont ER (2004): Use of the wings in manipulative and suspensory behaviors during feeding by frugivorous bats. J Exp Zool A Ecol Genet Physiol 301A:361366.

Vesselkin NP, Ermakova TV, Reperant J, Kosareva AA, Kenigfest NB (1980): The retinofugal and retinopetal systems in Lampetra fluviatilis. An experimental study using radioautographic and HRP methods. Brain Res 195:453-460.
Vonbartheld CS, Meyer DL (1987): Comparative neurology of the optic tectum in ray-finned fishes - patterns of lamination formed by retinotectal projections Brain Res 420:277288

Walls GL (1942): The Vertebrate Eye and Its Adaptive Radiation. New York, Hafner.

- Ward R, Reperant J, Hergueta S, Miceli D, Lemire M (1995): Ipsilateral visual projections in non-eutherian species: random variation in the central nervous system? Brain Res Rev 20:155-170.

Whishaw IQ, Sarna JR, Pellis SM (1998): Evidence for rodent-common and species-typical limb and digit use in eating, derived from a comparative analysis of ten rodent species. Behav Brain Res 96:79-91.

Whishaw IQ, Tomie JA (1989): Olfaction directs skilled forelimb reaching in the rat. Behav Brain Res 32:11-21.

Wicht H, Northcutt RG (1990): Retinofugal and retinopetal projections in the Pacific hagfish, Eptatretus stouti. Brain Behav Evol 36: 315-328.

-Wiggers W (1999): Projections of single retinal ganglion cells to the visual centers: an intracellular staining study in a plethodontid salamander. Vis Neurosci 16:435-447.

-Wiggers W, Roth G, Eurich C, Straub A (1995): Binocular depth perception mechanisms in tongue-projecting salamanders. J Comp Physiol A 176:365-377.

Wilga CD, Lauder GV (1999): Locomotion in sturgeon: function of the pectoral fins. J Exp Biol 202:2413-2432.

Williams SE, Mason CA, Herrera E (2004): The optic chiasm as a midline choice point. Curr Opin Neurobiol 14:51-60. 